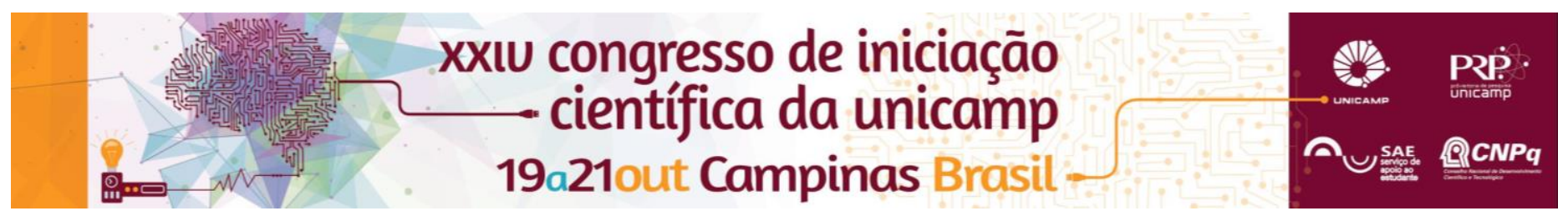

\title{
Ciclos Limites em Sistemas de Equações Diferenciais Planares Lineares por Partes
}

\author{
Mayara Duarte de Araujo Caldas*, Ricardo Miranda Martins.
}

\section{Resumo}

Neste trabalho consideramos sistemas de equações diferenciais planares lineares por partes em duas zonas, com o objetivo principal de estudar a existência de ciclos limite. Duas situações específicas foram estudadas com detalhe: o caso em que a variedade de descontinuidade é uma reta e também o caso em que a variedade de descontinuidade tem o formato de uma escada.

\section{Palavras-chave:}

Sistema de Filippov, Ciclos Limites, Variedade de Descontinuidade.

\section{Introdução}

O estudo de Sistemas de Equações Diferenciais Suaves por Partes surgiu da necessidade de descrever determinados fenômenos que não podem ser representados apenas com equações suaves. Este assunto é muito importante para diversas aplicações.

Neste sentido, surgiram vários estudos sobre o tema, por tratar de sistemas que apresentam comportamentos diferentes em determinados aspectos. Neste trabalho, estudamos um destes comportamentos: a existência de ciclos limites, que é o interesse principal do projeto, onde analisamos dois sistemas específicos com variedades de descontinuidade distintas.

\section{Resultados e Discussão}

Apoiados na literatura e em softwares, como o MatLab e o Maple, na primeira parte do projeto fizemos um estudo prévio dos seguintes tópicos:

i) Sistema de Filippov: estudando os conceitos básicos, com foco principal na variedade de descontinuidade, definindo região de costura, deslize e escape.

ii) Ciclos Limites: definindo órbita periódica regular, órbita de costura, órbita periódica deslizante, ciclo limite e sua estabilidade.

iii) Aplicação de Poincaré: estudando os conceitos básicos, possibilitamos encontrar os ciclos limites de um determinado sistema.

$\mathrm{Na}$ segunda parte, a partir dos estudos feitos anteriormente fizemos um estudo detalhado de duas situações especificas.

A existência de três ciclos limites em sistemas descontínuos por partes com duas zonas no plano em que a variedade de descontinuidade é uma reta, de modo que um sistema possua um foco real estável e o outro um foco virtual instável, tal que coincidem.

Inicialmente estudamos o comportamento do sistema com objetivo de determinar as regiões da variedade de descontinuidade, em seguida exploramos a demonstração deste resultado utilizando o Teorema de
Newton-Kantorovick e baseado em [2]. Além disso, definimos a estabilidade de cada ciclo limite do sistema.

Outro ponto considerado foi a e existência de sete ciclos limites em sistema descontínuos por partes com duas zonas no plano, baseado em [3], em que a variedade de descontinuidade é uma função que possui o formato de uma escada, que é uma ampliação da situação anterior, onde inicialmente consideramos um sistema mais geral que possui algumas condições, porém nos focamos em um sistema específico que satisfaz estas condições, para a análise deste resultado.

\section{Conclusões}

A proposta do projeto foi cumprida conforme o planejamento estipulado. Pretendemos ainda considerar outros tipos de sistemas lineares por partes, como por exemplo, o caso de três zonas e o caso em que a variedade de descontinuidade é inclinada.

\section{Agradecimentos}

Ao professor Dr. Ricardo Miranda Martins, pela orientação, ajuda e confiança.

À minha família, pelo apoio e incentivo.

Ao projeto "Equações Diferenciais Não-Linear" do PROCAD-Capes, por ter financiado esta pesquisa.

Otávio Marçal Leandro Gomide, Ciclos limites em Sistemas Dinâmicos Suaves e Não-Suaves. Universidade Estadual de Campinas, UNICAMP, 2015.

2 Ponce, E,; Llibre, J. Three Nested Limit Cycles in Discontinuous Piecewise Linear Differential Systems with Two Zones. Dynamics of Continuous Discrete and Impulsive Systems 19 (2012), 325-335.

3 Braga, C. D..; Mello, F. L. More Than Three Cycles in Discontinuous Piecewise Differential Systems with Two Zones in the Plane. International Journal Bifurcation and Chaos, vol. 24, n. 4 (2014) 1450056 (10 pages).

${ }^{4}$ Llibre J.; Teruel A. E., Introduction to the Qualitavie Theory of Differencial Systems: Planar, Symmetric and Continuous Prieciewise Linear Systems, Birkh“auser, 2014. 289 p. 